\title{
Translating evidence into impact: Enhancing health in Francophone West Africa and the Sahel
}

Population Council

Follow this and additional works at: https://knowledgecommons.popcouncil.org/

series_newsletters_researchimpact

How does access to this work benefit you? Let us know!

\section{Recommended Citation}

"Translating evidence into impact: Enhancing health in Francophone West Africa and the Sahel," Research Utilization and Impact Brief. Washington, DC: Population Council, 2022. 


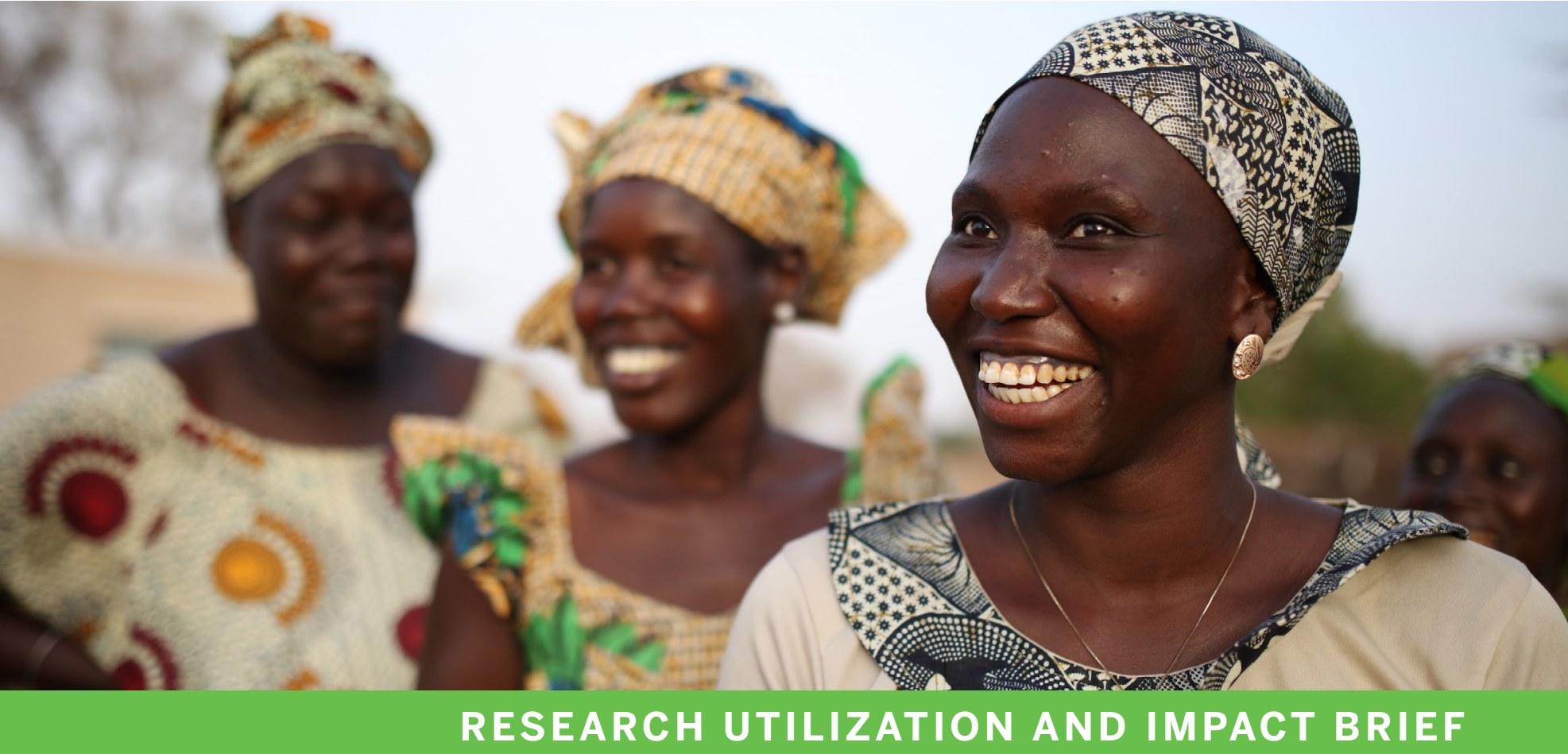

\section{Translating Evidence into Impact: Enhancing Health in Francophone West Africa and the Sahel}

\section{Summary}

- Over the past three decades, the

Population Council has worked to advance subnational, national, and regional efforts to improve health and promote evidence-based policies across Francophone West Africa (FWA).

- The Council has played a key role in supporting long-standing regional partnerships including the Ouagadougou Partnership Coordination Unit and West African Health Organization, as well as building the technical skills of local staff.

- Council research and technical assistance has informed policies and programs throughout FWA enhancing family planning, adolescent sexual and reproductive health, and efforts to prevent female genital cutting and mutilation and child marriage. Advocacy efforts have helped to foster enabling environments for access to comprehensive reproductive health services, including abortion.
Francophone West Africa (FWA) is a vibrant and diverse sub-region known for its strong national identities and regional collaboration. With high maternal and child death rates and low contraceptive prevalence compared to other parts of West Africa, Francophone countries have worked together to pursue common health and development goals, such as enhancing access to family planning/reproductive health $(\mathrm{FP} / \mathrm{RH})$; meeting the health, education, and employment needs of growing population of young people; and addressing challenges such as climate change and conflict. This politically, economically, and linguistically integrated subregion is characterized by partnerships and cooperative pacts, with regulatory agreements further enhancing sharing and adoption of tools, approaches, and best practices. While historically the sub-region has received less donor support relative to other areas of the Global South, actors such as the Population Council have remained committed to cultivating long-term partnerships, building local capacity, and generating and using evidence to address important issues.

The Population Council's engagement in FWA began in the 1980s, as it responded to national requests to enhance capacities in $\mathrm{FP} / \mathrm{RH}$ and 
other health areas. The resulting decades-long models of collaboration with national governments, including their health and $(\mathrm{MoH})$ and other ministries (e.g., family, youth), local authorities, national and international non-governmental organizations (NGOs), donors, and global normative agencies continues to strengthen critical host country partnerships and enhance the capacity to conduct responsive research. Over this period, the Council has also sustained collaborations with regional bodies such as the West African Health Organization (WAHO) and the Ouagadougou Partnership Coordination Unit (OPCU), OP's operational arm established in 2012. The Council has further participated in numerous Reproductive Health Supplies Coalition (RHSC) activities in FWA and contributed to its Francophone Forum (SECONAF) through extensive dissemination of members' research results.
The Council's work in FWA and the Sahel has included research activities, technical assistance, and collaborations across eleven countries: Benin, Burkina Faso Cameroon, Chad, Cote d'Ivoire, Guinea, Mali, Mauritania, Niger, Senegal, and Togo. Across these contexts, host country expertise, guidance, and partnerships have served as integral components of the Council's work, fostering investment at all levels of health systems and creating conditions for sustainable and locallyled action. Examples of key research topics include quality of care within clinical and youth $\mathrm{RH}$ services; mass media and social media campaigns for social and behavior change (SBC); adolescent girls' empowerment programming; maximizing human resources for health through task shifting/ sharing; and preventing child marriage and female genital mutilation and cutting (FGM/C).

\section{CURRENT \& RECENT COUNCIL PROJECTS IN FWA \& THE SAHEL}

Expanding Access to Family Planning and Sexual and Reproductive Health in Senegal and Francophone West Africa, Regional Advocacy for Enhanced Access to Safe Abortion Services, William and Flora Hewlett Foundation

Timeframe: 2012-2022

Geographic focus: Senegal and FWA region

Aim/Role: Provision of technical assistance, including collaboration with OP and other key partners, and support to the Best Practices Forum in Health, coconvened by the Economic Community of West African States (ECOWAS) and WAHO.
AmplifyPF, USAID

Timeframe: 2018-2023

Geographic focus: Burkina Faso,

Côte d'Ivoire, Niger, and Togo

Aim/Role: Quality assurance and monitoring for AmplifyPF project Pathfinder International (prime) to expand access to and utilization of quality family planning services in the West Africa region.
Breakthrough RESEARCH, USAID

Timeframe: 2017-2023

Geographic focus: Burkina Faso, Côte d'Ivoire, Mali, Niger, and Togo

Aim/Role: Generate and promote use of innovative SBC research, including expanding the global evidence base on effective SBC programming, to increase healthy behaviors and support healthy social norms.
Sahel Women's Empowerment and Demographic Dividend (SWEDD), UNFPA-West and Central Africa Regional Office Timeframe: 2019-2024 Geographic focus: Benin, Burkina Faso, Cameroon, Chad, Côte d'Ivoire, Guinea, Mali, Mauritania, and Niger Aim/Role: Provision of implementation support of adolescent girl-centered activities; monitoring, learning, and evaluation; and process documentation for World Bank initiative.
Recently Concluded Projects 2014-2021: USAID's global flagship HIV implementation science project, SOAR, with activities in Cameroon, Côte d'Ivoire, and Senegal.

2013-2021: USAID's global flagship FP implementation science project, Evidence, with activities in Burkina Faso and Senegal.

2017-2021: USAID-funded Frontline Health project with activities in Mali focused on measurement, learning, and evaluation of community-based healthcare delivery. 2015-2020: DFID-funded Evidence to End FGM/C research consortium, with activities in Burkina Faso and Senegal.

2016-2020: Netherlands Ministry of Foreign Affairs-funded More than Brides Alliance with activities in Mali and Niger evaluating the effectiveness of child marriage interventions.

2013-2018: USAID-funded Delivering Contraceptive Vaginal Rings, with activities in Senegal that led to the introduction of a new contraceptive method. 


\section{TIMELINE: HISTORY OF POPULATION COUNCIL IN FWA \& THE SAHEL}
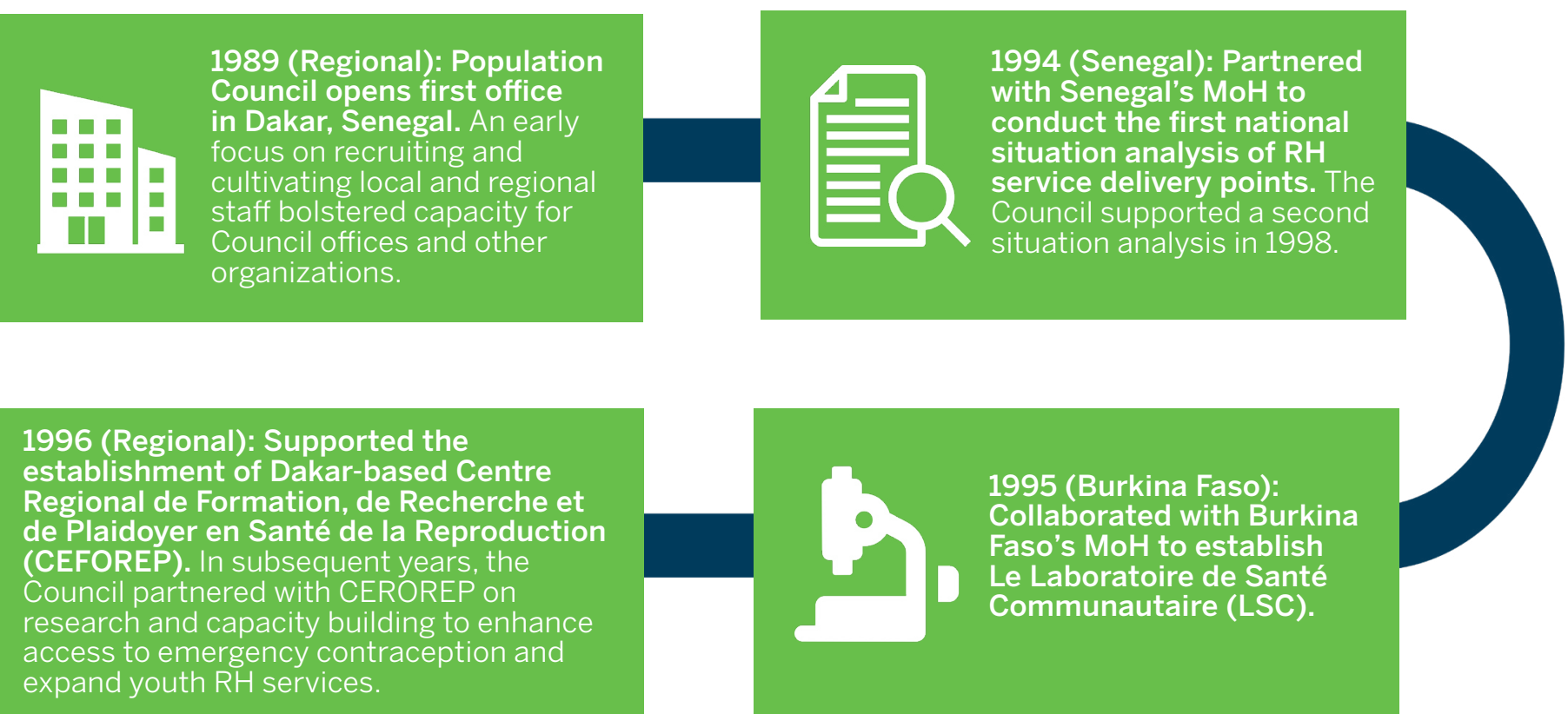

1996 (Regional): Supported the establishment of Dakar-based Centre Regional de Formation, de Recherche et de Plaidoyer en Santé de la Reproduction (CEFOREP). In subsequent years, the Council partnered with CEROREP on research and capacity building to enhance access to emergency contraception and expand youth RH services.
Late 1990s (Burkina Faso): Replicated Tostan's community commitment and dialogue intervention to eliminate FGM/C in Burkina Faso, testing its feasibility and effectiveness. Another Burkinabe NGO, Mwangaza Action, subsequently adapted and implemented the model across 23 villages.

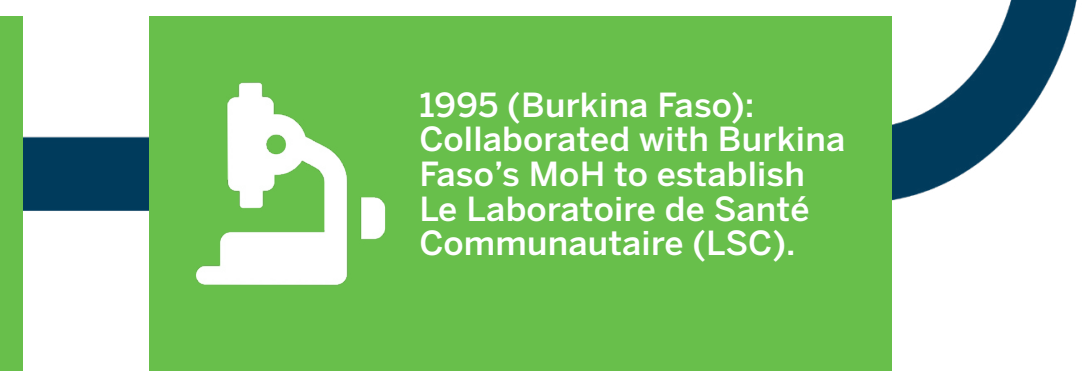

1997-2008 (Global): Led the USAID-funded Horizons HIV/AIDS operations research program with activities in Senegal to reach men who have sex with men. An early focus on generating public discussion around the needs of marginalized populations reinforced Council efforts to legitimize and address other sensitive topics such as FGM/C and post-abortion care.

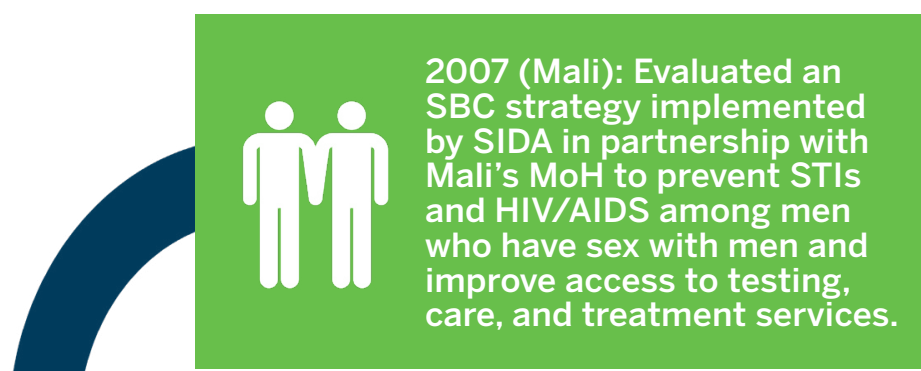

2005-2008 (Regional): Building on prior work on a strategic plan for female condom use in Senegal, partnered with national governments and UNFPA country offices to identify strategies for integrating female and male condoms into national RH and HIV/AIDS programs in Benin, Burkina Faso, and Mauritania.

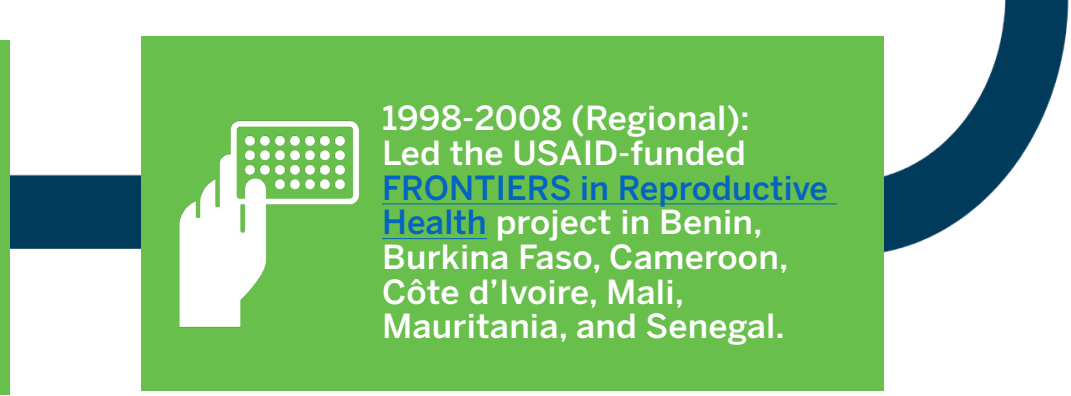

2009-2010 (Burkina Faso): Partnered with Burkina Faso's MoH to provide seconded staff and technical assistance to develop a national community health strategy. Evaluated MoH's obstetric fistula program and provided recommendations for future program design. 

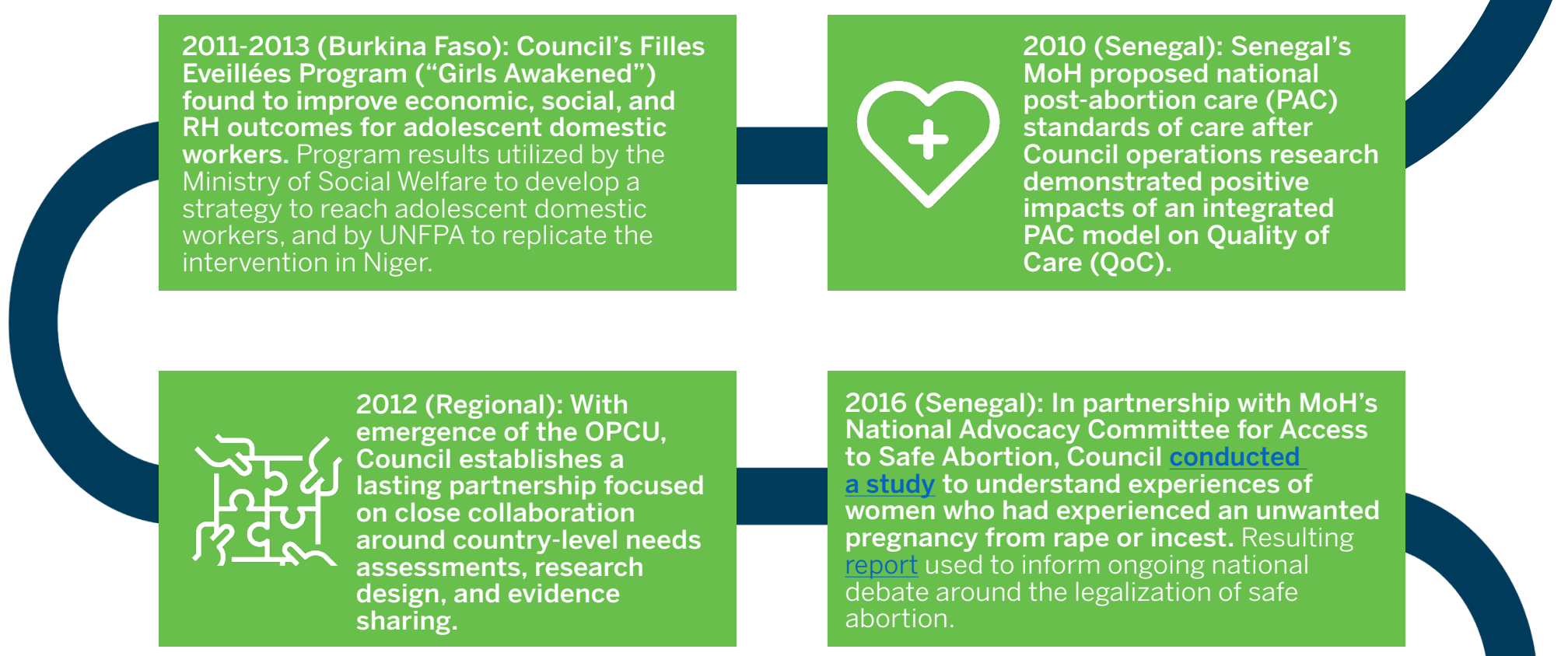

2010 (Senegal): Senegal's MoH proposed national post-abortion care (PAC) standards of care after Council operations research demonstrated positive PAC model on Quality of Care (QoC).

2020 (Senegal): Supported by an earlier Council acceptability study on the progesterone vaginal ring (PVR), Senegal becomes the first African country to register method for breastfeeding women. PC-Senegal remains engaged in process of developing national self-care guidance based on WHO recommendations which seek to include PVR.
2016 (Senegal): In partnership with MoH's National Advocacy Committee for Access to Safe Abortion, Council conducted a study to understand experiences of women who had experienced an unwanted pregnancy from rape or incest. Resulting report used to inform ongoing national debate around the legalization of safe abortion.

\section{RESEARCH UTILIZATION \& IMPACT}

Council research has directly informed policies and programs throughout FWA enhancing family planning, adolescent sexual and reproductive health, and efforts to prevent FGM/C and child marriage. Provision of technical assistance has also supported subnational, national, and regional institutionalization of $\mathrm{FP} / \mathrm{RH}$; maternal, newborn, and child health; adolescent girls' empowerment; and other health capacities. Research and advocacy efforts have fostered dialogue around creating supportive environments for access to safe abortion.

\section{Reinforcing Regional Partnership with the OPCU}

Since the OPCU was established in 2012, the Council has served as a trusted partner, closely collaborating to identify research ideas based on country needs and participating in co-design of
2017 (Regional): Building on engagement with Senegal's MoH and existing relationships with regional civil society and ministry partners, Council organized FWA's first regional workshop of advocacy committees and associations working to expand access to safe abortion, to enhance collaboration and information sharing. research activities. For instance, the Council and OPCU supported an activity with WAHO and the WHO's Regional Office for Africa to document the status of community-level task shifting for FP in all nine OP countries. A 2016 report synthesizing lessons learned was shared at a regional consultation, co-organized by WHO's Regional Office for Africa, OP, WAHO, and the Council that supported the development of national action plans for FP task shifting.

Since 2014, the Council and OPCU have also co-organized an annual journalism competition to promote news and commentary on $\mathrm{FP} / \mathrm{RH}$ in OP countries. Over this period, the Council has documented how these journalists' publications have fostered public discourse on FP/RH. At the eighth annual Ouagadougou Partnership meeting in December 2019, the Council shared key findings from an evaluation of the impact of the journalists' 
work on public discourse, policy, and program changes through the production of over 150 media pieces on reproductive health across the nine OP countries.

\section{Enhancing Opportunities for Girls in the Sahel}

Since 2019, the Population Council has worked with UNFPA's West and Central Africa Regional Office as a strategic partner in the World Bank's multi-country SWEDD Initiative. With national governments and implementing partners, the Council is providing technical assistance and learning and implementation support to improve the effectiveness and sustainability of activities to expand opportunities and reduce risks, such as school drop-out, child marriage, and early pregnancy for girls and young women living in poverty.

Based on in-country needs assessments of SWEDD "girl-centered" programming, including community and school-based safe spaces and economic empowerment activities, the Council successfully advocated with the World Bank and regional stakeholders for SWEDD's second phase to integrate core programming concepts such as segmented planning to account for the diversity of participants, intentional selection of communities, and adaptive management. Under SWEDD II, the Council continues to support countries to promote evidence-informed Espaces Sûrs (Safe Spaces) programming as coverage expands. Activities include promoting and supporting minimum standards to improve quality and targeting; monitoring, evaluation, and learning; process documentation; mentor management; and coping with COVID-19.

\section{Supporting National FP/RH Planning Efforts in Senegal}

Over several decades, the Council has worked to expand method choice in Senegal's evolving legal and regulatory environment, supporting efforts to enhance access to quality services via onestop-shops and task shifting, as well as advancing emergency contraception. In 2016, the Evidence Project evaluated Senegal's 2012-2015

National Family Planning Action Plan (NFPAP), which was based on a "3D Approach"

(Democratization, De-Medicalization, Decentralization). Among the first OP countries to develop a NFPAP, the Council documented lessons learned from Senegal's implementation of this approach which were shared by OPCU with other neighboring countries. In close collaboration with the Ministry of Health and USAID/Senegal, this research also informed development of Senegal's subsequent National Family Planning Strategic

\section{PARTNERSHIP HIGHLIGHTS}

\section{TRUSTED REGIONAL PARTER}

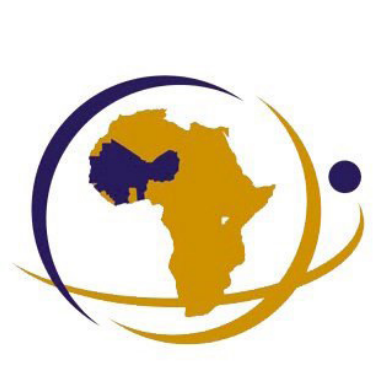

With the OPCU, the Council has supported development of national plans for FP task shifting, and an annual journalism contest to enhance public discourse, policy, and program change.

\section{VALUED TECHNICAL COLLABORATOR}

With the World Bank and UNFPA, the Council has enhanced girl-centered programming, providing technical assistance for this multi-national initiative initiated at the request of Sahel national governments.

\section{RESPONSIVE NATIONAL RESOURCE}

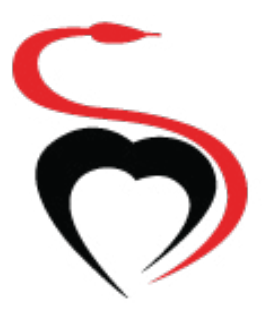

Ministère de la Santé et de l'Action Sociale
With Senegal's Ministry of Health and Social Action, the Council evaluated the region's first National Family Planning Action Plan and is supporting a third national CIP. 
Framework (2016-20). To advance national FP goals outlined in the NFPAP, the Council further supported an assessment of private pharmacist provision of contraceptives at the request of the Ministry of Health and other partners. The Evidence Project published a package of two briefs and three reports assessing the legal and non-legal obstacles to private pharmacy provision of FP services, along with qualitative and quantitative data to inform policy recommendations. This evidence is contributing to the development of Senegal's third national CIP and supporting regional dialogue around task shifting for FP and expanding the role of the private sector.

\section{LOOKING FORWARD}

Going forward, the Council will continue to work closely with national and regional partners to support key priorities across FWA. With the emergence of new regional commitments for FP2030 and a new OP strategy, the Council remains a trusted contributor and advisor, participating in planning sessions and providing technical support to Ministries and other partners.

In alignment with these regional efforts, the Council looks forward to continuing its support for introduction of new evidence-based tools and approaches through cross-country exchange and collaboration. It is poised to respond to evolving human resource needs and changing strategies that seek greater involvement of the private sector. It will maintain its focus on advancing sexual and reproductive health and rights through projects on task shifting and self-care, safe abortion access, improving opportunities for girls, and addressing infertility within universal health care efforts. Within a growing regional ecosystem of partners and investments focused on building resilient communities, addressing climate change, and promoting peace and governance, the Council remains a committed partner in FWA, prepared to address emerging health and development challenges.

The Population Council collaborates with program implementers, policymakers, researchers, and funding partners to advance evidence-based solutions to critical health and development challenges. Its research utilization and impact briefs feature recent highlights of our ongoing work to ensure evidence is translated into meaningful actions to improve lives from community to national, regional, and global levels.

Recommended citation: "Translating Evidence into Impact: Enhancing Health in Francophone West Africa." Research Utilization and Impact Brief. Washington, DC. Population Council, 2022.

Cover Photo: (C) Dominic Chavez/The Global Financing Facility

\begin{tabular}{|c|c|}
\hline \multicolumn{2}{|c|}{ RECENT EXAMPLE RESEARCH PRODUCTS } \\
\hline OPCU & 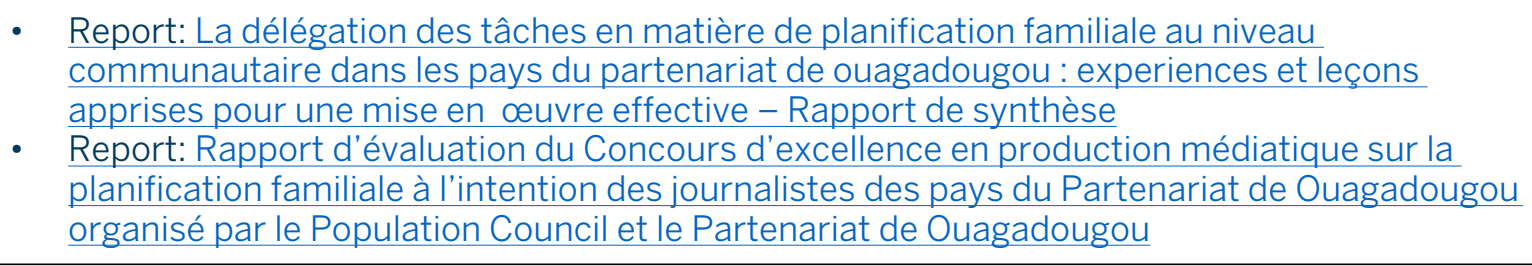 \\
\hline SWEDD & $\begin{array}{l}\text { - Guide: Le Guide des Normes Minimales pour des Espaces Sûrs : la conception, la mise en } \\
\text { - } \frac{\text { Touvre, et le suivi, l'évaluation et l'apprentissage }}{\text { Toolkit: Valoriser le potentiel des mentores Recrutement, formation et soutien des }} \\
\text { - } \frac{\text { mentores pour des programmes dédiés aux adolescentes }}{\text { Brief: Prise De Mesures Pour Les Adolescentes En Periode De La Covid-19; Implications }} \\
\text { Pour La Programmation Des Espaces Sûrs Au Sahel }\end{array}$ \\
\hline $\begin{array}{l}\text { FP in } \\
\text { Senegal }\end{array}$ & 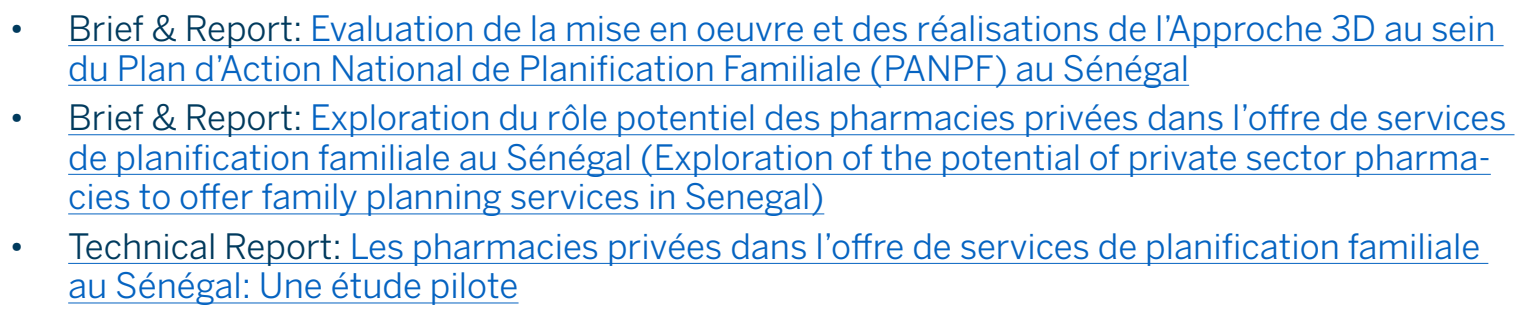 \\
\hline
\end{tabular}

